\title{
Kansei Games: Entertaining Emotions
}

\author{
Ben Salem \\ Department of Industrial Design, Eindhoven University of Technology, The Netherlands \\ also, School of Science and Technology, Kansai Gakuin University, Japan \\ mail@bsalem.info
}

\begin{abstract}
We introduce and describe the concept of Kansei Game as the implementation of Kansei Mediated Entertainment. In our current approach we translate the classical Zen story of ten Ox herding pictures into a game. We describe the features of such a game and we propose some guidelines for its design and development.
\end{abstract}

Keywords: Games, Kansei mediation, entertainment, Ox Herding, Zen.

\section{Introduction}

Essentially Kansei Games are a new concept of games that focus on delivering a constructive positive experience to the game player. We wish to do this by addressing the player needs, requirements and desires. Salem and Rauterberg [1] propose a Needs Requirements and Desires (NRD) model where the self is at the centre, and all needs requirements and desires radiate from it. It is an egocentric, egoistic and hedonistic model. In which, needs relates to the essentials, requirements to the necessary and desires to the optional. While playing a game, it is possible to assess its usage in terms of its effect on the player's NRD. We believe that the fulfillment of the NRD would yield a positive game experience. We would like to propose an approach that addresses user's NRD and results in enrichment, positive affect and inner balance for the user.

\section{What Is Kansei}

Originally, Kansei engineering was defined as the translating of a consumer feelings and image of a product into some of the design elements used to create that product [2]. Kansei Engineering is about addressing user's "real needs" through ergonomic technology that addresses feelings and sensations [3]. Furthermore it was defined as a consumer oriented technology for the creation of new products. It was subdivided into forwards and hybrid Kansei Engineering [4], [5]. In the first instance, subjective information from consumers is fed into the design process. In the second instance there is also a flow of information from the design process towards the consumer. Whereby design ideas and directions are tested and assessed by the consumers. Kansei Design is also about consumer subjective impressions [6]. It is an affective design approach that involves a mapping process between the consumer's affective needs and the designer's perceptual design elements. Kansei design addresses the optimisation of the affective 
description of a product. In contrast to addressing the emotional needs of a product user. In this perspective, Khalid [7] propose Hedonomics as the study of emotions in the valuation of products and Citarasa Engineering $(\mathrm{CE})$ as engineering that addresses consumer emotional intent and aspirations. In a sense, $\mathrm{CE}$ is about designing products that will fulfil the consumer emotional needs. We aspire to go further and deal with the aesthetic of the user experience through the fulfilment of his/her objective (usability, ergonomics) and subjective (affect, experience) needs, requirements and desires.

Another approach into understanding Kansei Design is to look at the values it deals with. Kansei values are being subjective, multivocal and ambiguous [8]. They are subjective in that the information belongs to the thinking person rather than the object of thoughts. The values are multivocal in that they can have different meaning of equal probability and validity. They are ambiguous because they have several meanings and interpretations.

How could Kansei value and Design be relevant to the design of a game? Rather than move towards a mathematical modelling of Kansei Engineering, see for example [6], we would like to move towards a set of design rules and guidelines. We advocate this approach, because we believe that ultimately the design of an Kansei Game should be considered an end rather than mean. A Kansei Game should deliver an experience that is effective, efficient and satisfactory. These are similar to the guidelines of ISO 9241 [9]. However, in that standard effectiveness is described as accuracy and completeness, efficiency relates to the expenditure of resources and satisfaction to the freedom from discomfort and the attitude towards usage. In our case we expend these definitions. Effectiveness relates to how good the system is at causing/achieving the desired results. Efficiency is about how minimal are the resources to achieve the desired results. As for user satisfaction relates to the user experience and its aesthetics (see [10]).

\subsection{The Concept of Kansei Game}

We propose a new concept of games that is based on Kansei. As such, a Kansei Game cannot be a game with clear objectives such as goals to reach or races to win. It has to have game mechanics that translate Kansei values into game rules and play. To help us in this direction we refer to popular stories of Zen culture such as the Ox Herding pictures that help explain how to reach Satori (a form of enlightenment). Furthermore, we have to investigate the selection of media and modalities that should be used within a Kansei Game to deliver an enriching user experience. Fig. 1, list some of the various media, modalities that are used for communication between humans. These are text, discourse, sound for explicit media. Voice tone, appearance, distance for implicit media. Body language, eye gaze, cultural references and wording of sentences for Kansei media.

Combined, explicit, implicit and Kansei media, form a rich channel of communication that should be implemented in Kansei Games as far as possible. This is even more important, because as human we are particularly sensitive to combination of media when building our perception. Human perception is a combination of sensory (what our senses tell us), synesthetic (the combination of senses), autonomic (what our guts tell us), motor (the quality of body movements) and cognitive (what our mind tells us) information. 


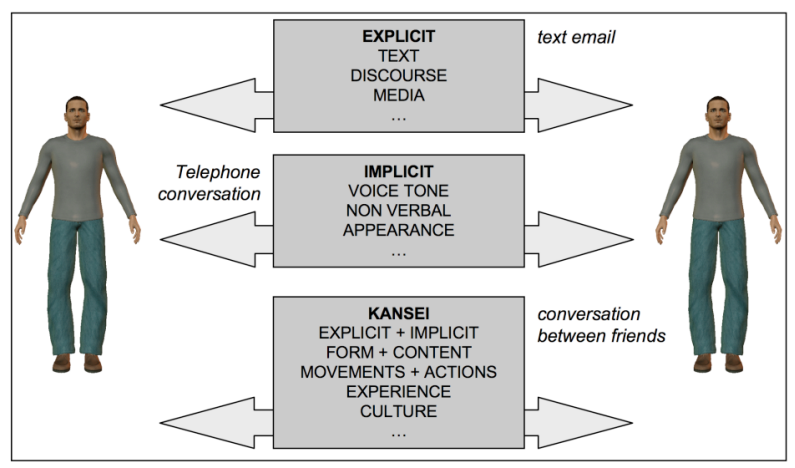

Fig. 1. Explicit, Implicit and Kansei Communication and Interface

Therefore a Kansei Game will rely on a combination of media, modalities and Kansei communication to deliver a rich positive user experience. However how to select the right combination of media, modalities and Kansei communication is an issue that need addressing during the development of the first proposed game.

\section{Narrative}

For the first implementation of a Kansei Game, we propose the story of the Ox Herding as a narrative for the game [11]. It is a well documented story that helps explain enlightenment and Satori.

This short story has ten steps:

1. Seeking the ox: Starting the journey, while being unaware that a dualist approach cannot lead to the understanding of the true nature of mind. There should not be a mind/body separation.

2. Seeing the ox tracks: Although the ox is still not seen, the tracks confirm its existence, and lead to way to it. Through self-discipline and training, it is possible to rediscover one's true self.

3. Seeing the Ox: The path to enlightenment has been seen. It is about finding one's true self, through trial and errors.

4. Catching the Ox: Although the ox has been seen, the difficulty now is to catch it.

5. Herding the Ox: Kencho is finally obtained after a long period of disciplinary training. However, the Kencho attained is only a stepping stone towards Satori.

6. Coming Home on the Ox Back: The efforts paid off. The ox and the herder move together effortlessly. This shows the state in which one completely finds one's true self, that is, the state in which one obtains Satori.

7. Ox is forgotten: The ox and the herder become one. Dualism has been overcome and the herder has no worldly attachments any more.

8. Both Ox and self-forgotten: The separation of reality from the mind is gone. Enlightenment is experienced and the mind has escaped.

9. Returning to the source: Back to square one. The world carries on as always.

10. Returning to help others: The enlightened has renounced all to selflessly help others. 
The ten Ox Herding Pictures are an imagery of an illusion to be negated before a seeker can experience enlightenment. In these pictures, the ox symbolises the mind, while the herder the seeker. The illusion being that reality is separate from the mind. These metaphorical steps help one achieves Kensho and Satori. The story is a metaphor; it is not based on a character performing some specific actions. The story is about discovering the deeper meanings of events and behaviours. We would like to implement this story as a game made up of interface iterations/interface choreography based on multimedia, multimodal and Kansei media.

\section{Game Mechanics}

The mechanics of a Kansei game are based on the understanding that this is not a game with an end goal but a software toy. In similar fashion to SimCity and ATrainHX. The objectives are not competitive and the game is a form of interactive story. In our proposal the game is about relaxing and reaching inner balance, peace of mind and calmness. It is not about achieving a particular goal in terms of user actions and behaviour within the game. It is about nurturing a certain attitude and mood of quietness, calmness and inner balance. This implies a self-awareness and a selfcontrol from the user.

The mechanics proposed are those of a role-playing game, whereby the user is identified as the Ox-herder. But instead of the user having to play the role (behaviour) of the Ox-herder as if it were a fictional character, s/he has to control her/his attitude, mood and arousal levels (inner state) as if they were those for Ox-herder. In other words, with Kansei games it is not about adopting the behaviour of a fictional character but about transferring to the Ox-herder one's inner state. It is a transfer of inner state rather than a transfer of behaviour.

Furthermore, in line with role-playing games, the user will have to follow a story (in our case the 10 Ox-Herding pictures story). Within the framework of the story the players can improvise freely, however, the outcome and direction of the game will depend on their inner state rather than their actions.

\section{Game Play}

In essence the gameplay applicable to Kansei Games is that of a combination of adventure games and role-playing games. Both gameplays are very similar with the first focusing more on puzzle solving, and interaction with the game character (Oxherder).

In our case focusing on how to herd the Ox. In order to progress in the game narrative, the player has to help the character, the Ox-herder, achieve his aims, and thus catch and domesticate the Ox. Overall the game adventure can be treated as a finite state machine with transition conditions mainly related to the player inner state, emotions and moods. The game emphasis on the player's interpretation of the scenery and of the game mechanics make Kansei Games Puzzle adventures with plots that are 
not necessarily understood first time. Because the games are played from a first person perspective, the user is encouraged to decipher the game mechanics as soon as possible, and to map her/his actions and state to the game character attributes.

There are many attributes to the Ox-herder that are used as part of the story We call these attributes original ones. A second set of attributes of the Ox-herder are a result of the transfer of the player inner state, we call these acquired ones.

\begin{tabular}{lll}
\hline \multicolumn{1}{c}{ Domain } & \multicolumn{1}{c}{ Original } & \multicolumn{1}{c}{ Acquired } \\
\hline Stamina & $\begin{array}{l}\text { Necessary level to wander } \\
\text { around the scenery }\end{array}$ & $\begin{array}{l}\text { Increases with lower arousal levels } \\
\text { as related to heart rate and blood } \\
\text { pressure. }\end{array}$ \\
\hline Dexterity & Close to none & $\begin{array}{l}\text { Increases with better inner balance } \\
\text { as related to body posture, and } \\
\text { movements. }\end{array}$ \\
\hline Effectiveness & $\begin{array}{l}\text { Slow movement pace and } \\
\text { irregular walking stride. }\end{array}$ & $\begin{array}{l}\text { Increases with calmness as related } \\
\text { to galvanic skin conductance. }\end{array}$ \\
\hline
\end{tabular}

Within the game we propose three different reward systems for the player. Namely, level, skills and experience. The level reward is essentially about moving from one level of the game to the next. In this present context from one of the 10 Ox-Herder pictures to the next. The skills reward is linked to the improvement of the user inner state and is translated into a better (from the game perspective) set of attributes and resources of the Ox-herder. Finally the experience reward is related to the improvement of the positive experience the player is having, through a deeper and wider self-awareness and self control.

The game quest is about herding the Ox. It is a non-linear gameplay, in the sense that the game progresses regardless of the player either progressing towards herding the $\mathrm{Ox}$ or getting further away from achieving this. Furthermore, the game can be perceived as being about herding the Ox, reaching a better inner-balance, achieving a wider self-awareness or a deeper self-control, or any combination thereof.

The only one encounter there is in the game is that of crossing first the path of the Ox shadows, the Ox track and then encountering the Ox.

Regarding the interaction during gameplay, it will be based on both user actions on selected interaction devices (e.g. mouse, keyboard, gamepad...), as well as on the monitoring of the player physiological parameters (e.g. galvanic skin conductance, body heat, heart rate, blood pressure and body posture...).

\section{Conclusion}

Through this paper we have attempted to describe the development on a Kansei Game as the implementation of Kansei Mediated Entertainment. While only early stages of the game development are explained, we hope to show a clear direction in the development of this new game genre that is about encouraging player to attain a higher level of self-consciousness and a better inner balance. Furthermore, we would like to encourage the development of games that find inspiration in art and religious installations that have proven successful in influencing for the better people's minds. 


\section{References}

1. Salem, B., Rauterberg, M.: Multiple User Profile Merging: Key Challenges for Aware Environments. In: Harper, R., Rauterberg, M., Combetto, M. (eds.) ICEC 2006. LNCS, vol. 4161, pp. 103-116. Springer, Heidelberg (2006)

2. Nagamachi, M.: Kansei Engineering: A New Ergonomic Consumer-Oriented Technology for Product Development. International Journal of Industrial Ergonomics 15, 3-11 (1995)

3. Nagamachi, M.: Kansei Engineering and Comfort. International Journal of Industrial Ergonomics 19, 79-80 (1997)

4. Matsubara, Y., Nagamachi, M.: Hybrid Kansei Engineering System and Design Support. International Journal of Industrial Ergonomics 19, 81-92 (1997)

5. Nagamachi, M.: Kansei Engineering as a Powerful Consumer-Oriented Technology for Product Development. Applied Ergonomics 33, 289-294 (2002)

6. Jiao, J.R., Zhang, Y., Helander, M.: A Kansei Mining System for Affective Design. Expert Systems with Applications 30, 658-673 (2006)

7. Khalid, H.M.: Embracing Diversity in User Needs for Affective Design. Applied Ergonomics 37, 409-418 (2006)

8. Hashimoto, S.: Advanced Human-Machine Interface and Humanoid Robot for Kansei Communication. In: Proc. IECON 2000, pp. 493-498 (2000)

9. ISO: Ergonomic requirements for office work with visual display terminals (VDTs)- Part 11: Guidance on usability, ISO 9241-11:1998(E) (1984)

10. Jordan, P.W.: Human Factors for Pleasure in Product Use. Applied Ergonomics 29(1), 22-25 (1998)

11. Salem, B., Rauterberg, M., Nakatsu, R.: Kansei Mediated Entertainment. In: Harper, R., Rauterberg, M., Combetto, M. (eds.) ICEC 2006. LNCS, vol. 4161, pp. 103-116. Springer, Heidelberg (2006) 